\title{
Pharmacovigilance during treatment of multiple sclerosis: early recognition of CNS complications
}

\author{
Martijn T Wijburg (1) ,1,2 Clemens Warnke 이, ${ }^{3,4}$ Christopher McGuigan, ${ }^{5}$ \\ Igor J Koralnik, ${ }^{6}$ Frederik Barkhof, ${ }^{2,7}$ Joep Killestein, ${ }^{1}$ Mike P Wattjes ${ }^{2,8}$
}

For numbered affiliations see end of article.

\section{Correspondence to} Dr Martijn T Wijburg, Department of Neurology, MS Center Amsterdam, Neuroscience Amsterdam, Amsterdam UMC, Vrije Universiteit, 1081 HV Amsterdam, Noord-Holland, The Netherlands; m.wijburg@ vumc.nl

Received 10 July 2020 Revised 27 September 2020 Accepted 5 October 2020 Published Online First 23 November 2020

\begin{abstract}
An increasing number of highly effective diseasemodifying therapies for people with multiple sclerosis (MS) have recently gained marketing approval. While the beneficial effects of these drugs in terms of clinical and imaging outcome measures is welcomed, these therapeutics are associated with substance-specific or group-specific adverse events that include severe and fatal complications. These adverse events comprise both infectious and non-infectious complications that can occur within, or outside of the central nervous system (CNS). Awareness and risk assessment strategies thus require interdisciplinary management, and robust clinical and paraclinical surveillance strategies. In this review, we discuss the current role of MRI in safety monitoring during pharmacovigilance of patients treated with (selective) immune suppressive therapies for MS. MRI, particularly brain MRI, has a pivotal role in the early diagnosis of CNS complications that potentially are severely debilitating and may even be lethal. Early recognition of such CNS complications may improve functional outcome and survival, and thus knowledge on MRI features of treatment-associated complications is of paramount importance to MS clinicians, but also of relevance to general neurologists and radiologists.
\end{abstract}

\section{INTRODUCTION}

In the past decades, a number of new and successful disease-modifying treatments (DMTs) for multiple sclerosis (MS) have become available. These DMTs have different modes of action, and some represent a 'first-in-class' drug with a long-term safety profile still to be established. As several new drugs are currently in phase 3 trials, the number of available DMTs is likely to increase in the coming years. Recently approved DMTs for MS generally have an immunosuppressive potential that translates into an increasing efficacy, superior in clinical studies to the older injectable platform therapies such as glatiramer acetate or interferon beta.

Selection of DMTs based on potential benefits must be balanced with rare to frequent, and potentially serious, adverse events seen with the newer drugs. ${ }^{1}$ These adverse events include infectious and non-infectious disorders outside of, but often also involving, the central nervous system (CNS). ${ }^{2}$ In this review, we present and discuss the current data on the role of MRI in safety monitoring during pharmacovigilance of MS therapies, which aims at the early detection of CNS complications to facilitate the timely initiation of appropriate management and subsequently better outcome. ${ }^{3}$

\section{The role of MRI in MS}

The important role of MRI in the (differential) diagnosis of MS has irrefutably been established. ${ }^{4}$ With the increasing number of available DMTs for MS, MRI has become an important tool to assess and monitor treatment efficacy. More recently, the role of MRI in patients with MS has expanded to safety monitoring purposes including the detection of infectious and non-infectious adverse events affecting the CNS. ${ }^{3}$ As such, the application of MRI during pharmacovigilance of MS therapies (which should always be considered in the context of clinical vigilance and paraclinical tests) includes three major aims.

- To detect treatment failure/loss of response in clinically stable patients by detecting new or enlarging lesions suggestive of active MS. ${ }^{3}$

- To screen patients at risk of severe adverse events without new neurological symptoms for asymptomatic lesions suggestive of CNS adverse events.

- To evaluate patients with new neurological symptoms to rapidly differentiate MS disease activity from CNS adverse events.

This review will focus on the latter two aims, with an emphasis on specific MRI findings that can be essential for diagnosis, as well as on risk factors and clinical signs in different infectious and noninfectious DMT related adverse events (see online supplemental file 1 for search strategy and selection criteria).

\section{INFECTIOUS ADVERSE EVENTS \\ $\mathrm{JC}$ virus-associated diseases}

JC virus (JCV)-associated diseases include a partially overlapping spectrum of entities, with progressive multifocal leukoencephalopathy (PML) being the most well known. Following primary infection, which is asymptomatic in most healthy persons, JCV remains latent or causes asymptomatic persistent infection in the gastrointestinal tract, kidneys, bone marrow and lymphoid tissue, ${ }^{5}$ although the relevant reservoir is still unknown. In immunocompromised patients, JCV may cross the blood brain barrier, possibly via infected B-cells, ${ }^{6}$ and cause a lytic infection of oligodendrocytes, astrocytes and neurons leading to PML. ${ }^{7}$ In addition, JCV can cause a productive and lytic infection of predominantly granule cell neurons, resulting 
in cerebellar atrophy and cerebellar symptoms, named granule cell neuronopathy (GCN). ${ }^{89}$ More rare JCV-associated diseases are JCV encephalopathy ${ }^{10}$ and JCV meningitis. ${ }^{11}$ Intraindividual acquisition of PML-type variants of the viral genome may be a prerequisite for CNS infection and tropism for oligodendrocytes, astrocytes or neurons during immunosuppression and may explain the different syndromes of JCV-associated diseases. ${ }^{7} 12$ JCV-associated CNS diseases have traditionally been reported in varied states of immunodeficiency such as HIV/AIDS. ${ }^{13}$ More recently, PML and GCN have been associated with general and selective immunosuppressive treatments of autoimmune diseases. ${ }^{14}$ PML can be difficult to diagnose and is often initially misdiagnosed. ${ }^{15}$

\section{JCV in MS therapies}

In MS pharmacovigilance, PML and GCN are the most relevant JCV entities. Among the DMTs, natalizumab is by far the drug most frequently associated with JCV-associated complications. Natalizumab is a monoclonal antibody against the $\alpha 4$-integrin adhesion molecule which inhibits transmigration of immune cells through the blood-brain barrier into the CNS and is used for the treatment of relapsing forms of MS. ${ }^{16}$ As of 2 March 2020, 832 confirmed cases of natalizumab-associated PML had been reported ( $>208.354$ patients treated). ${ }^{17}$ PML has also been observed in patients with MS treated with fingolimod, dimethyl fumarate, alemtuzumab and ocrelizumab. As of 1 March 2020, 37 cases of PML have been reported in patients treated with fingolimod (>299 600 patients treated), 10 cases in patients treated with dimethyl fumarate ( $>445000$ patients treated), and one with alemtuzumab, without prior treatment with natalizumab. ${ }^{18-22}$ In addition, PML has been reported in patients treated with rituximab (a chimeric anti-CD20 monoclonal antibody leading to B-cell depletion), for example, for haematological malignancies or systemic lupus erythematosus, but not during off-label treatment for MS. In patients using ocrelizumab, a recently approved humanized anti-CD20 monoclonal antibody (>150 000 patients treated), only one case of PML has been reported that is not attributable to prior treatment with another DMT, although PML occurrence in this patient might have been confounded by immunosenescence and low baseline lymphocyte counts. ${ }^{23}$ Several cases of PML have been reported following natalizumab treatment cessation, one also following fingolimod cessation, and subsequent initiation of another DMT, and thus are considered the so-called 'carry-over' cases, attributed to the prior treatment with natalizumab or fingolimod. As the latency between discontinuation of natalizumab and development or recognition of PML can vary, the risk of 'carry-over' PML, poses an additional challenge for clinicians with regards to MS pharmacovigilance. $^{24} 25$ Carry-over PML also brings the risk of aggravating PML disease course by initiation of a subsequent DMT prior to PML detection, especially lymphocyte depleting treatments. This may have been the case with a lethal case of carry-over PML in a patient receiving alemtuzumab following natalizumab. ${ }^{26}$

Several factors are associated with an increased risk for PML during natalizumab treatment. First, while the risk for PML is low in patients who are seronegative for JCV, this risk increases significantly in anti-JCV antibody positive patients and is even higher in those with a high anti-JCV antibody index. ${ }^{27}$ Furthermore, the risk for PML during natalizumab treatment is increased in patients who were previously treated with older immunosuppressive drugs (azathioprine, mitoxantrone, cyclophosphamide), as well as patients with a natalizumab treatment duration of $\geq 18$ months. ${ }^{27}$ It has been suggested that extending dosing intervals of natalizumab reduces the risk of PML, although this risk is still not negligible. ${ }^{28} 29$

Another strategy for PML risk assessment has been introduced for patients treated with dimethyl fumarate and comprises regular monitoring of absolute lymphocyte count in peripheral blood, as low lymphocyte counts appear to be associated with the development of PML in these patients. ${ }^{21} 30$ However, PML may also develop in patients treated with dimethyl fumarate without significant lymphopenia, ${ }^{31}$ and current recommendations are based on a very limited number of cases and controls. So far, no specific method for risk assessment for PML development has been determined with fingolimod treatment. Older age might be a risk factor independent of the underlying therapy that causes PML. ${ }^{20} 3233$

\section{MRI pharmacovigilance}

PML lesions typically present as T2 and fluid attenuation inversion recovery (FLAIR) hyperintense subcortical lesions with an isointense to hypointense signal on T1-weighted images (depending on disease stage and extent of demyelination) and are most frequently located in the frontal lobe followed by parietal and occipital lobe (figure 1, table 1). ${ }^{34}$ PML lesions frequently involve the cortical grey matter and may also be located infratentorial or in the deep grey matter. ${ }^{34} 3637$ In addition, small punctate lesions with a perivascular distribution can be observed on T2/FLAIR sequences, which is regarded relatively specific for PML. ${ }^{3638}$ Contrast enhancement is present in approximately one-third of the patients at PML diagnosis, generally with patchy enhancement in the border of the PML lesion, but small punctate enhancing lesions can also be observed. ${ }^{39}$ Diffusion weighted imaging (DWI) may reveal restricted diffusion associated with acute demyelination and thereby may assist in differentiating acute PML lesions from chronic or subacute MS lesion. ${ }^{40}$ GCN is characterised by progressive cerebellar atrophy on MRI either as a sole imaging finding, or concomitantly to classical PML lesions (figure 1 , table 1$).^{841}$

In patients at high risk for PML, expected efficacy and potential risks should be carefully weighed, also taking into account the expected efficacy and risk of an alternative treatment, and the risk of severe MS rebound following treatment cessation. ${ }^{42}$ For high-risk patients, enhanced pharmacovigilance is recommended including higher frequency (3-4 months) of MRI follow-up examinations. ${ }^{3} 43$ This recommendation is supported by the observational evidence that presymptomatic PML lesions could be detected in $78 \%$ of patients with natalizumab-associated PML during a period of approximately 5 months prior to symptom onset or formal diagnosis based on a positive MRI. ${ }^{44}$ Presymptomatic lesion detection leads to an improved survival and functional outcome, ${ }^{34}$ and frequent MRI surveillance leads to detection of significantly smaller PML lesion volumes and less disability at detection. ${ }^{43}$ Recent expert panel guidelines propose frequent MRI screening, every 3 to 4 months, using an abbreviated MRI protocol consisting of at least FLAIR, T2-weighted, and DWI sequences in patients at high risk for PML during natalizumab treatment, at the time of treatment cessation prior to introduction of a new DMT, and at least until 6 months after natalizumab discontinuation. ${ }^{346}$

This approach has been challenged, ${ }^{47}$ and indeed, asymptomatic PML lesion detection and differentiation from new MS lesions can be difficult, leading to a delay in diagnosis. Sensitivity and specificity of MRI for the diagnosis of asymptomatic natalizumab-associated PML on follow-up MRI of 

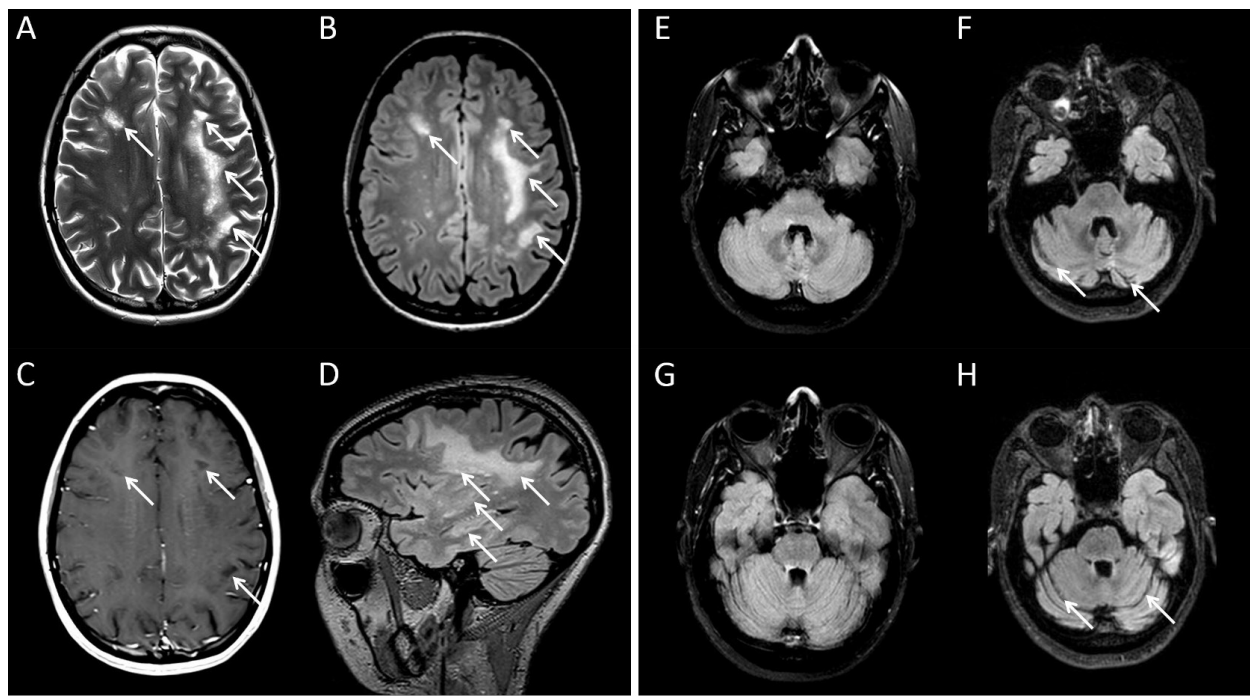

Figure 1 MRI of a patient with natalizumab-associated progressive multifocal leukoencephalopathy (PML) (A-D) and an MRI of a patient with signs of granule cell neuronopathy (GCN) concomitant to natalizumab-associated PML (E-H). Axial T2 (A), fluid attenuation inversion recovery (FLAIR) (B) and contrast enhanced T1 (C), and sagittal FLAIR images (D). Multifocal, confluent, T2 and FLAIR hyperintense lesions are visible in the frontal, parietal and temporal lobes, mostly located in the juxtacortical white matter extending in, and spreading through, the deep white matter. On T2, the lesions show a microcystic appearance. Parts of the lesions show a hypointense signal on T1. Axial FLAIR images prior to diagnosis $(\mathrm{E}, \mathrm{G})$ and at the time of PML with concomitant GCN diagnosis 3 months later $(F, H)$. Note the appearance of cerebellar atrophy with bilateral dilated sulci on the follow-up images, with no infratentorial white matter PML lesions visible.

91\% and 100\%, respectively, have been reported when using a standardised imaging protocol on the same MRI scanner and based on consensus reading by three neuroradiologists. ${ }^{37}$ When specifically testing the differentiation of asymptomatic PML from new MS lesions on MRI follow-up in a real-world natalizumab pharmacovigilance setting, a sensitivity of $74.2 \%$ and specificity of $84.7 \%$ with only a moderate inter-rater agreement was observed. ${ }^{48}$ This suggests the relevance of high neuroradiological expertise for the reading of surveillance MRIs, which should always be seen in the context of clinical and paraclinical information. The need for making an accurate differentiation between new MS lesions and asymptomatic PML lesions is further increased given the contradictory treatments. Incorrectly excluding PML will result in ongoing damage due to infection and, conversely, an erroneous suspicion of PML may lead to cessation of natalizumab and thus inadequate immunosuppression in a patient with MS disease activity.

In case of PML suspicion based on clinical symptoms and/or MRI results, the diagnosis of PML can be further established by demonstration of JCV DNA in CSF by PCR. ${ }^{49}$ However, JCV DNA can be undetectable in both asymptomatic as well as symptomatic patients, hampering a diagnosis of PML. ${ }^{25} 5051$ Indeed, patients with smaller PML lesion volumes more frequently have a negative PCR, ${ }^{52}$ indicating that CSF in patients suspected for PML should be tested in reference laboratories with a very low limit of detection (around $10 \mathrm{cp} / \mathrm{mL}$ CSF). Furthermore, additional tests such as the assessment for the intrathecally produced anti-JCV antibody fraction or the lesion evolution on MRI may support the diagnosis in some cases. ${ }^{44} 53-55$

\section{Herpesviruses}

Herpes simplex virus (HSV) is an ubiquitous virus of the herpesvirus family. There are two subtypes, HSV-1 and HSV-2. HSV-1 is a common and highly contagious virus and the WHO has recently estimated that $67 \%$ of the human population under the age of 50 years is carrier of HSV-1 with the virus remaining latent in neural ganglia. ${ }^{56} \mathrm{HSV}-2$ is less frequent, but still a highly prevalent and almost exclusively sexually transmitted virus with the virus remaining latent in the sacral ganglia. Although rare, with an estimated incidence of 1 in 250000 to 500000 per year, ${ }^{57}$ herpes simplex encephalitis (HSE), predominantly caused by reactivation of the HSV-1 virus, is the most common cause for sporadic encephalitis that can occur in both immunocompetent and immunocompromised individuals. HSE carries a considerable morbidity and mortality. HSV PCR in CSF is used to confirm the diagnosis. Varicella zoster virus (VZV) also belongs to the family of herpesviruses, and has been reported to cause CNS infections, such as VZV encephalitis. Prompt initiation of antiviral treatment is essential. ${ }^{58}$

\section{Herpesviruses in MS therapies}

In 2013, Fine et al reported 20 cases of CNS herpesvirus infections in patients treated with natalizumab based on postmarketing reports received by the US Food and Drug Administration (FDA). ${ }^{59}$ Of these patients, 11 had HSE, 8 patients had meningitis (6 HSV and $2 \mathrm{VZV}), 1$ had meningoradiculitis (VZV), and 1 meningomyelitis (VZV). In other reports, VZV myelitis, meningovasculitis and retinitis associated with CNS vasculitis have been described in patients treated with natalizumab. ${ }^{60-62}$ Although it is difficult to assess the risk for HSV-related CNS disease, the authors found that the number of patients with HSE appears to be over-represented in patients treated with natalizumab when comparing to the background incidence. In addition, fingolimod treatment increases the risk for VZV infections, mostly herpes zoster but at least four cases of VZV encephalitis have been described. ${ }^{63-66}$ Therefore, vaccination is recommended for patients without varicella immunity before starting fingolimod. ${ }^{67}$ Fingolimod also appears to be associated with an increased risk for HSV infections with two cases of HSE reported. ${ }^{668}$ Recently, one case of HSE has been reported in a case treated with dimethyl fumarate with a marked decline in blood lymphocytes prior to HSE development. ${ }^{69}$ Finally, 
Table 1 Basic MRI features of infectious and non-infectious adverse events during multiple sclerosis (MS) therapies

\begin{tabular}{|c|c|c|c|}
\hline & Location & Shape/appearance & MRI sequences \\
\hline \multicolumn{4}{|l|}{$J C V$} \\
\hline$P M L$ & $\begin{array}{l}\text { Juxtacortical WM, infiltrating adjacent GM } \\
\text { Extending in deep WM } \\
\text { Can start in cortical or deep GM } \\
\text { Infratentorial in } 10 \%\end{array}$ & $\begin{array}{l}\text { Unifocal or multifocal, later diffuse/confluent } \\
\text { Spreading via WM tracts } \\
\text { Punctate lesions with perivascular distribution } \\
\text { Microcystic appearance on T2 } \\
\text { Later: development of PML-IRIS: patchy/punctuate } \\
\text { contrast enhancement lesion border and swelling }\end{array}$ & $\begin{array}{l}\text { T2/FLAIR hyperintense } \\
\text { T1 isointense or hypointense (especially later as } \\
\text { demyelinisation progresses) } \\
\text { Contrast enhancement in } 30 \%\end{array}$ \\
\hline GCN & $\begin{array}{l}\text { Cerebellum } \\
\text { Sometimes concomitant PML lesions (infratentorial and/or } \\
\text { supratentorial) }\end{array}$ & $\begin{array}{l}\text { Cerebellar atrophy } \\
\text { Sometimes 'hot cross bun sign' }\end{array}$ & $\begin{array}{l}\text { T1 and T2 shows atrophy } \\
\text { T2 and FLAIR show 'hot cross bun sign' } \\
\text { T2 and FLAIR show PML lesions }\end{array}$ \\
\hline \multicolumn{4}{|l|}{ Herpesviruses } \\
\hline HSE & $\begin{array}{l}\text { Temporal lobe(s)/insular in } 80 \% \\
\text { Extratemporal in } 55 \% \text { : brainstem, cerebellum, cortical or a } \\
\text { combination }\end{array}$ & $\begin{array}{l}\text { Starting in cortex, spreading along limbic pathways } \\
\text { Later spreading parietal, occipital, brainstem }\end{array}$ & T2/FLAIR hyperintense and T1 hypointense \\
\hline VZV & $\begin{array}{l}\text { Meninges } \\
\text { Cortex/parenchyma } \\
\text { Spinal cord } \\
\text { Large and small intracranial vessels } \\
\text { or a combination of the above }\end{array}$ & $\begin{array}{l}\text { Meningitis } \\
\text { Cortical/parenchymal lesions (encephalitis) } \\
\text { Myelitis } \\
\text { Irregularities and dilation (vasculopathy) of large } \\
\text { vessels, and ischaemic lesions }\end{array}$ & $\begin{array}{l}\text { Meningeal contrast enhancement } \\
\text { T2/FLAIR hyperintense cortex/parenchyma } \\
\text { MRA vasculopathy, DWI/ADC map ischemia }\end{array}$ \\
\hline Cryptococcus & $\begin{array}{l}\text { Meninges } \\
\text { Parenchymal gelatinous pseudocysts } \\
\text { Parenchymal cryptococcomas in mesencephalon and basal } \\
\text { ganglia }\end{array}$ & $\begin{array}{l}\text { Meningitis in } 69 \% \\
\text { Dilated perivascular spaces } \\
\text { Hydrocephalus } \\
\text { Gelatinous pseudocysts: 'soap bubble' appearance } \\
\text { Single or multiple round cryptococcoma masses }\end{array}$ & $\begin{array}{l}\text { Meningeal contrast enhancement } \\
\text { Cryptococcomas and pseudocysts T2 and FLAIR } \\
\text { hyperintense and T1 hypointense } \\
\text { Cryptococcomas homogeneous or ring } \\
\text { enhancement }\end{array}$ \\
\hline Listeriosis & Brainststem, cerebellum and/or thalamus & $\begin{array}{l}\text { Subcortical abscesses in the thalamus, pons and } \\
\text { medulla } \\
\text { Cerebritis }\end{array}$ & $\begin{array}{l}\text { T2/FLAIR hyperintense } \\
\text { T1 hypointense or isointense } \\
\text { DWI hyperintense } \\
\text { ADC map hypointense } \\
\text { Ring enhancement and/or cranial nerve } \\
\text { enhancement }\end{array}$ \\
\hline Nocardiosis & $\begin{array}{l}\text { Brain parenchyma } \\
\text { Meninges }\end{array}$ & $\begin{array}{l}\text { Parenchymal brain abscess (often multiple) } \\
\text { Meningitis }\end{array}$ & $\begin{array}{l}\text { T1 with rim enhancement } \\
\text { Diffusion restriction (including low ADC) } \\
\text { Meningeal contrast enhancement }\end{array}$ \\
\hline RCVS & $\begin{array}{l}\text { Infarcts and haemorrhage typically in watershed areas } \\
\text { Infarcts usually bilateral and symmetrical } \\
\text { Oedema in posterior regions }\end{array}$ & $\begin{array}{l}\text { Cerebral infarction (39\%) } \\
\text { Convexity SAH (34\%) } \\
\text { Lobar haemorrhage }(20 \%) \\
\text { Oedema resembling PRES }\end{array}$ & $\begin{array}{l}\text { Fitting ischaemia, SAH or lobar haemorrhage } \\
\text { 'String of beads' on vascular imaging; bilateral } \\
\text { narrowing of all intracerebral arteries }\end{array}$ \\
\hline PRES & $\begin{array}{l}\text { Bilateral parieto-occipital region in } 70 \% \\
\text { Also frequently superior frontal sulcus or watershed pattern }\end{array}$ & Vasogenic oedema & $\begin{array}{l}\text { T2/FLAIR hyperintense } \\
\text { ADC hyperintense } \\
\text { Contrast enhancement in } 20 \%\end{array}$ \\
\hline PCNSL & $\begin{array}{l}\text { Cerebral hemispheres (38\%) } \\
\text { Basal ganglia and thalamus (16\%) } \\
\text { Corpus callosum (14\%) }\end{array}$ & $\begin{array}{l}\text { Mostly a single lesion (65\%) } \\
\text { Often near CSF } \\
\text { Moderate perifocal oedema }\end{array}$ & $\begin{array}{l}\text { Often contrast enhancement } \\
\text { T2/FLAIR often isointense but shows perifocal } \\
\text { oedema }\end{array}$ \\
\hline TDL & - Mostly supratentorial in frontal and parietal lobes & $\begin{array}{l}\text { Large lesions } \\
\text { Mass effect }(45 \%) \\
\text { Oedema }(77 \%)\end{array}$ & $\begin{array}{l}\text { T2/FLAIR hyperintense } \\
\text { T2 hypodense ring surrounding lesion } \\
\text { Almost always contrast enhancement (eg, open- } \\
\text { ring enhancement) }\end{array}$ \\
\hline
\end{tabular}

Cerebrovascular events (in patients treated with alemtuzumab) are not included in this table due to the diversity of reported events in patients treated with alemtuzumab, which on its own are radiologically similar to those seen in patients with a primarily cardiovascular cause for the event.

ADC, apparent diffusion coefficient; CSF, cerebral spinal fluid; DWI, diffusion weighted imaging; FLAIR, fluid attenuation inversion recovery; GCN, granule cell neuronopathy; GM, grey matter; IRIS, immune reconstitution inflammatory syndrome; JCV, JC virus; MRA, magnetic resonance angiography; PCNSL, primary central nervous system lymphoma; PML, progressive multifocal leukoencephalopathy; PRES, posterior reversible encephalopathy syndrome; RCVS, reversible cerebral vasoconstriction syndrome; SAH, subarachnoidal haemorrhage; TDL, tumefactive demyelinating lesion; WM, white matter.

cladribine, ocrelizumab and alemtuzumab all increase the risk for mucocutaneous herpes infections (both HSV and VZV), ${ }^{70} 71$ but so far only two patients with MS who developed herpes infection of the CNS were reported in association with these drugs (herpes meningitis in a patient treated with alemtuzumab and HSE in a patient treated with ocrelizumab). ${ }^{72} 73$ Prophylactic acyclovir treatment is recommended for 1 month following initiation of each course of alemtuzumab (alemtuzumab Summary of Product Characteristics (SPC)).

\section{MRI pharmacovigilance}

Patients with HSE usually present with acute change in mentation or focal neurological deficits, sometimes in combination with fever and seizures. MRI typically shows lesions in the temporal lobe, although extratemporal abnormalities occur and can even be the only visible abnormality $(55 \%$ and $15 \%$, respectively, in one study; figure 2 , table 1). ${ }^{74}$ Another study showed that in immunocompromised patients HSE can have a more atypical manifestation, showing more extensive brain involvement including atypical regions and excluding the temporal lobe on MRI, regularly with normal cell counts in the CSF, and a substantial increase of morbidity and mortality. ${ }^{75}$ With VZV infection of the CNS, MRI may show no abnormalities, vascular lesions (both haemorrhagic and ischaemic), vasculitis, meningitis, myelitis, non-specific abnormalities, or a combination of these (figure 2, table 1). ${ }^{6276}$ As development and progression of CNS infection are probably always very rapid, regular MRI screening is not an option. Therefore, clinical vigilance and awareness of the risk of herpesvirus infections in patients treated with natalizumab, fingolimod, alemtuzumab and ocrelizumab, and with MRI as part of the diagnostic workup, may be warranted.

\section{Cryptococcus}

Cryptococcus is an encapsulated yeast often found in bird excrements which may enter the human body via inhalation of spores, potentially causing serious pulmonary infections and/ or meningoencephalitis. Cryptococcus neoformans is the type most commonly infecting humans, and is mostly observed in 

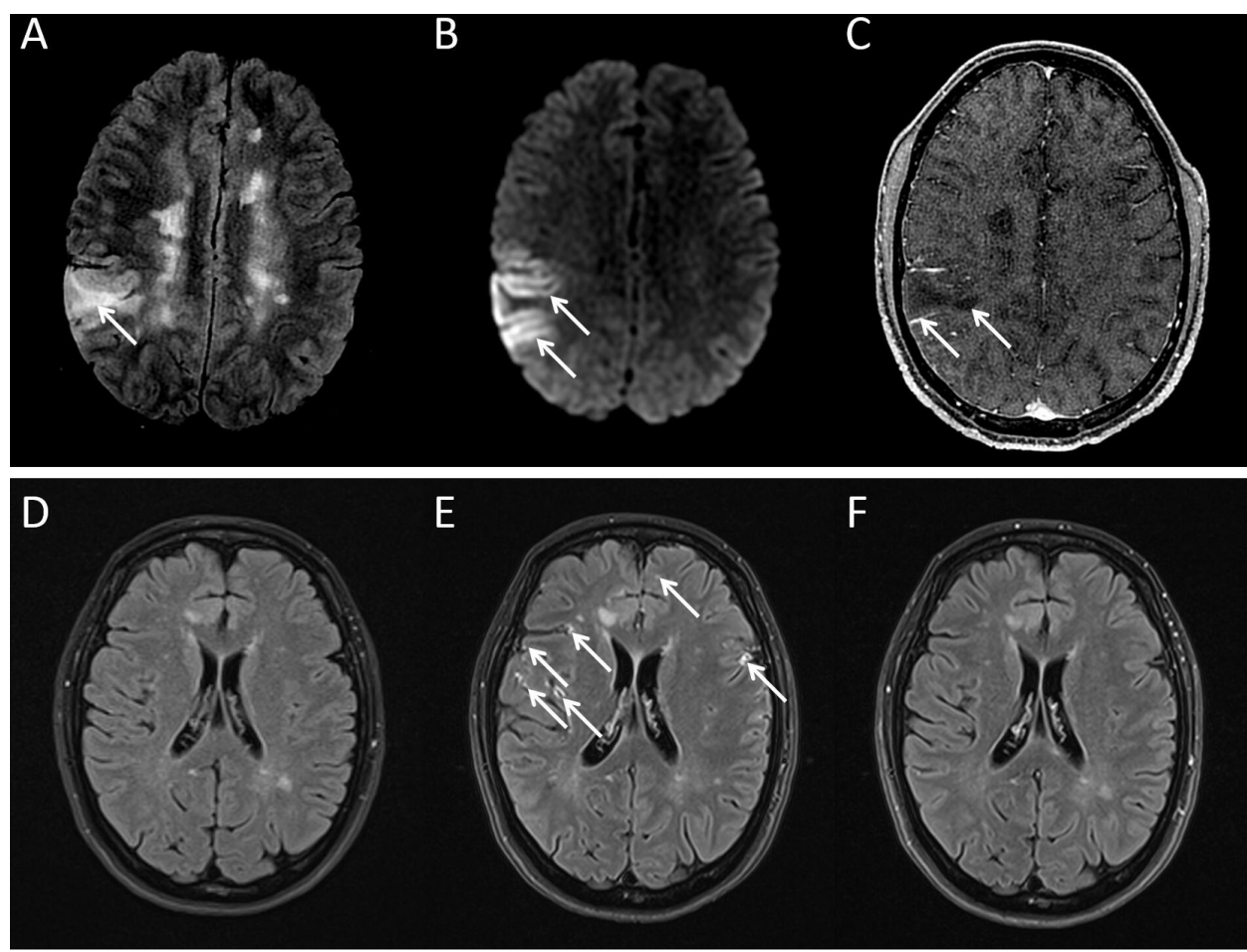

Figure 2 MRI of a patient with herpes simplex virus encephalitis during treatment with natalizumab $(A-C)$ and a MRI of a patient with varicella zoster meningovasculitis during treatment with natalizumab (D-F). Axial fluid attenuation inversion recovery (FLAIR) (A), diffusion weighted imaging (DWI) (B), and contrast enhanced T1 (C). A lesion in the right parietal lobe is visible, showing a high signal intensity of both cortical grey matter and juxtacortical white matter on FLAIR images. The cortical part of the lesion shows a high signal intensity on DWI. On T1, the juxtacortical part of the lesion shows a low signal intensity and meningeal enhancement. Also note the swelling in and around the lesion. Axial FLAIR image 3 months prior to diagnosis (D), contrastenhanced axial FLAIR at diagnosis (E), and contrast enhanced axial FLAIR 3 months following diagnosis and treatment with acyclovir (F). Several small nodular leptomeningeal lesions are visible in both frontal lobes. Similar lesions were visible infratentorial and on the spinal cord, and MR angiography showed signs of vasculitis.

immunocompromised patients. ${ }^{77}$ It is believed that C. neoformans causes an asymptomatic focal pneumonitis following inhalation resulting in a latent infection, with a risk for reactivation on immunosuppression. ${ }^{78}$ In HIV-infected patients, cryptococcal meningitis predominantly affects patients with CD4 counts $<100$ cells $/ \mu \mathrm{L}^{79}$ Diagnosis is mostly based on a rapid cryptococcal antigen test in CSF.

\section{Cryptococcus in MS therapies}

In 2015, a case of cryptococcal meningoencephalitis was reported in a patient with MS treated with fingolimod, ${ }^{80}$ and until now 10 cases have been published. ${ }^{81}{ }^{82}$ In addition, cases with disseminated cryptococcal infection with both a CNS and dermal and/ or pulmonary involvement were reported. ${ }^{81}$ Immunosenescence appears to play an important role in the development of cryptococcal meningoencephalitis in fingolimod treated patients, with an increased risk for patients that are older, have a longer treatment duration (which induces immunosenescence-like changes), and have low CD4 counts. ${ }^{83}$ In natalizumab-treated patients, two cases of cryptococcal meningitis have been reported, one of whom died from immune reconstitution inflammatory syndrome within a week after initiation of antifungal therapy. ${ }^{84} 85$ Recently, a first case of cryptococcal meningitis has been described in a patient treated with dimethyl fumarate, despite normal absolute lymphocyte counts and absence of other risk factors. ${ }^{86}$

Several cases of cryptococcal meningitis have been reported in patients treated with rituximab, alemtuzumab and cladribine for other indications, such as leukaemia, rheumatoid arthritis, and organ transplantations, but so far not for MS. ${ }^{87-89}$ In these patients, a potential link with the drug is obscured by their comorbidities and additional treatments with other chemotherapies or immunosuppressive drugs, which contributed to the impaired immune status.

\section{MRI pharmacovigilance}

Patients with cryptococcal meningoencephalitis typically present with headache, fever and malaise. A recent study investigated imaging findings of cryptococcal meningitis in $114 \mathrm{HIV}$-negative patients and found $69 \%$ of patients showing characteristic lesions of cryptococcal meningitis on brain MRI. ${ }^{90}$ The most common findings were general signs of meningitis (either pachymenineal or leptomenineal enhancement), followed by dilated perivascular spaces, hydrocephalus, intracerebral nodules, and pseudocysts (figure 3 , table 1). ${ }^{90}$ As cryptococcal meningoencephalitis tends to develop swiftly, it is unlikely that frequent MRI scanning would detect the disease in a presymptomatic stage. Therefore, awareness and clinical vigilance with respect to the occurrence of cryptococcal infections particularly in patients treated with fingolimod, natalizumab or dimethyl fumarate remains crucial, especially in older patients and those with a longer fingolimod treatment duration.

\section{Listeria}

Listeriosis is caused by the gram-positive anaerobic bacterium Listeria monocytogenes. The main route for infection is through contaminated food such as raw meat and fish, shellfish, uncooked vegetables, unpasteurized dairy products, and 

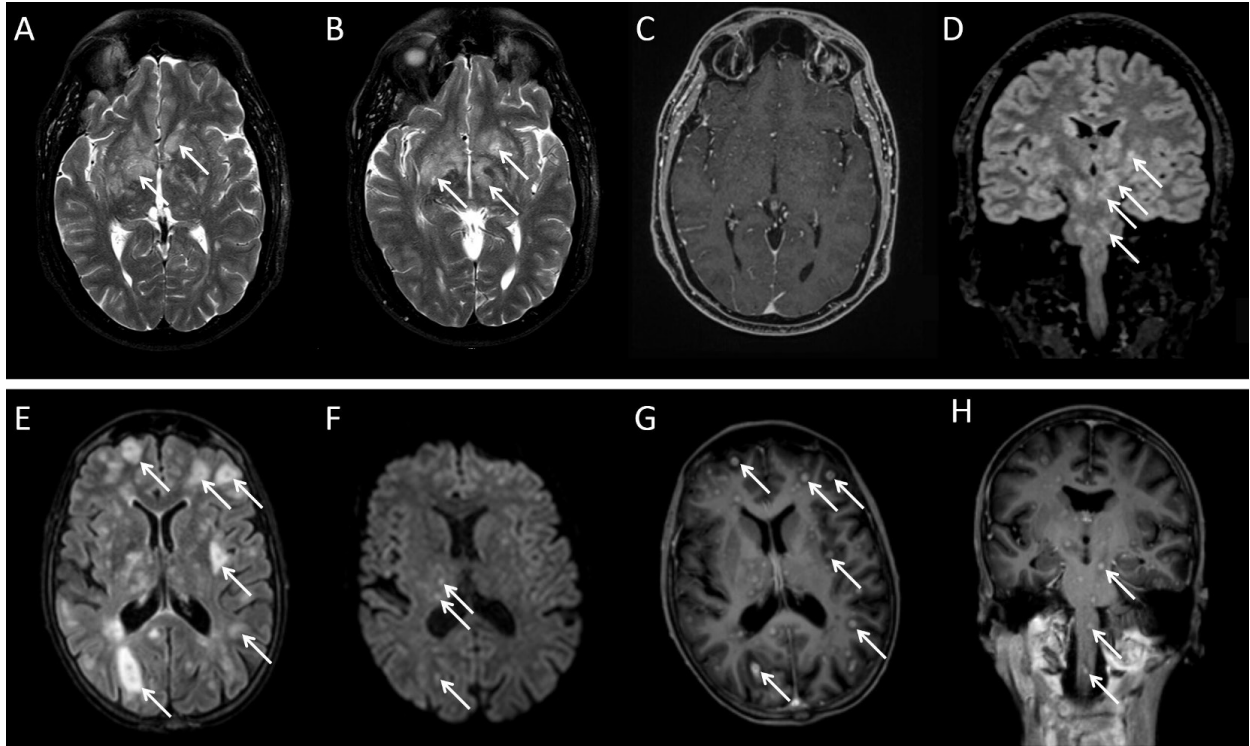

Figure $3 \mathrm{MRI}$ of a patient with cryptococcal meningoencephalitis during treatment with fingolimod (A-D) and an MRI of a patient with central nervous system nocardiosis following treatment with alemtuzumab (E-H). Axial T2 ( $A, B)$ and contrast enhanced T1 (C), and coronal fluid attenuation inversion recovery (FLAIR) images (D). Non-enhancing T2 and FLAIR hyperintense lesions in the basal ganglia (cryptococcomas). Panel D shows spread of cryptococcomas through the mesencephalon into the pons. Axial FLAIR (E), diffusion weighted imaging (F) and contrast enhanced T1 (G), and coronal contrast enhanced T1 images $(\mathrm{H})$. Multiple small brain abscesses with ring enhancement are visible in the supratentorial brain parenchyma, with surrounding oedema and some showing subtle diffusion restriction. Also note the spread of the abscesses infratentorial and in the spinal cord.

soft cheeses. Listeriosis is mostly reported with one of the three following presentations: bacteraemia, meningoencephalitis and maternofetal or neonatal listeriosis, and has a fatality rate of $20 \%-30 \% .{ }^{91}$ Depending on the country, the incidence of listeriosis varies between 0.1 and 11.3/1 000 000, predominantly affecting immunocompromised patients, elderly, pregnant women and their fetuses, and neonates. ${ }^{91}$ In addition, listeriosis may present as self-limiting gastroenteritis in immunocompetent individuals, which likely is hugely underdiagnosed due to the non-specific symptoms. ${ }^{91}$

\section{Listeriosis in MS therapies}

Since 2008, several cases of listeria meningitis in patients with MS treated with alemtuzumab have been reported. A comprehensive series of 22 cases of listeriosis associated with alemtuzumab published in the literature and/or reported to VigiBase (an international database of suspected adverse drug reactions from the WHO) was reported by Holmøy et al in 2017. ${ }^{92}$ Although some cases lacked information on the indication for treatment, and on the clinical presentation and/or clinical outcome, at least 16 of the 22 patients were treated for MS (first or second cycle), 9 of whom presented with meningitis/meningoencephalitis, 2 with sepsis, and 5 with an unknown presentation, and at least 3 patients died. ${ }^{92}$ At the time of publication, approximately 11 500 patients with MS had been treated with alemtuzumab and thus, the authors calculated, the incidence of listeriosis appears to be around $0.1 \%(16 / 11500) .{ }^{92}$ Following alemtuzumab treatment, CD4(+) and CD8(+) T cells and dendritic cells, crucial in controlling the infection, are rapidly depleted from circulation and cytokine release is impaired. ${ }^{93} 94$ Interestingly, in several of the reported cases, symptoms of listeriosis developed within days after or even during the alemtuzumab treatment cycle. ${ }^{92}$ Recently, two cases of listeria induced rhombencephalitis have been reported, one with dimethyl fumarate treatment and one with fingolimod treatment. ${ }^{95} 96$ Although, no cases of listeria meningitis have been reported in patients treated for MS with
B-cell or lymphocyte depleting therapies such as rituximab, ocrelizumab and cladribine; five have been reported with rituximab for other indications. ${ }^{97}$

\section{MRI pharmacovigilance}

Brain MRI can reveal signs of leptomeningitis, lesions suggestive of encephalitis and abscess formation. Specifically, listeria can cause rhombencephalitis, affecting primarily the brainstem and cerebellum (table 1). ${ }^{98}$ Listeriosis develops rapidly, and as specific risk factors in alemtuzumab treated patients have not yet been identified and the incidence is low, MRI screening for CNS listeria infection is not justified. Prevention of listeriosis by adhering to a listeria-free diet starting 2 weeks prior to treatment, during treatment, and at least 1 month following an alemtuzumab treatment cycle, as recommended in the SPC, may prevent infection. In addition, cotrimoxazole is often prescribed as listeria prophylaxis for 1 month following initiation of each alemtuzumab cycle. ${ }^{99}$

\section{Nocardia}

Nocardiosis is caused by the gram-positive aerobic bacteria Nocardia, containing a total of 85 subspecies of which some are pathogenic. Most infections are acquired through inhalation or via traumatic skin lesions and generally occur as an opportunistic infection in immunocompromised patients, especially those with an impaired cell-mediated immune response. ${ }^{100}$ The most frequent clinical presentation is pulmonary nocardiosis; however, the disease can disseminate through haematological spreading and affects the CNS in up to $44 \%$ of patients. ${ }^{101}$

\section{Nocardiosis in MS therapies}

Until now, only two cases of nocardiosis during treatment of MS, both treated with alemtuzumab, have been reported, one with CNS nocardiosis and one with pulmonary nocardiosis. ${ }^{102} 103$ The patient with CNS nocardiosis presented with a tetraspastic 
syndrome 4 months after the first cycle of alemtuzumab and diagnosis was finally made through culture of intracranial abscess material acquired via biopsy, as broad screening of both blood and CSF returned negative. ${ }^{102}$ Patients treated with rituximab for other indications have also developed nocardiosis ${ }^{104}$; however, comorbidities and concomitant therapies may have contributed to the development of nocardiosis in these patients.

\section{MRI pharmacovigilance}

Most patients with CNS nocardiosis present with confusion, followed (in order of frequency) by weakness, speech impairment and headache and only rarely with meningism. ${ }^{101}$ The vast majority of patients with CNS nocardiosis show formation of a parenchymal abscess, evidenced by a ring-enhancing lesion on MRI (figure 3, table 1). ${ }^{101}$ However, space-occupying lesions can be invisible. In a minority of patients, the disease manifests as meningitis, with or without associated brain abscess. ${ }^{105}$ Due to the low incidence, MRI screening for CNS nocardiosis is not useful.

\section{NON-INFECTIOUS ADVERSE EVENTS}

Reversible cerebral vasoconstriction syndrome and posterior reversible encephalopathy syndrome

Reversible cerebral vasoconstriction syndrome (RCVS) is believed to be caused by segmental constriction of cerebral arteries which often is spontaneously reversible within 3 months after onset, and generally presents with thunderclap headache and, less frequently, with focal neurological deficits or seizures. ${ }^{106}$ RCVS is associated with the posterior reversible encephalopathy syndrome (PRES), which is characterised by headache, confusion, visual symptoms and seizures and is clearly associated with hypertension. ${ }^{107}$ Indeed, RCVS and PRES share overlapping pathophysiology. ${ }^{108}$ RCVS and PRES are both associated with autoimmune diseases, but also with immunosuppressive drugs. Almost half of patients with PRES have a history of autoimmune disease, and in at least half of patients with RCVS the disease was preceded by treatment with vasoactive drugs or childbirth. ${ }^{106} 107$
RCVS and PRES in MS therapies

The link between MS therapies and RCVS and PRES is anecdotal and includes several case reports. RCVS has been reported in two patients treated with fingolimod ${ }^{109} 110$ and one patient treated with interferon beta $1-\mathrm{a} .{ }^{111}$ Furthermore, PRES has been reported in patients treated with fingolimod, ${ }^{112}$ natalizumab ${ }^{113}$ and high-dose corticosteroids. ${ }^{114}$ However, VigiBase reports a total of 34 and 7 cases of PRES and RCVS, respectively, in patients treated with fingolimod and 9 cases of PRES in natalizumab treated patients. ${ }^{115}$ Although these numbers should be interpreted with caution and should not be used to calculate incidences in relation to DMTs, as no causal relation is proven and comorbidities may play a role, they do suggest that PRES and RCVS may complicate MS therapies more frequently than previously assumed.

\section{MRI pharmacovigilance}

RCVS can be complicated by stroke, subarachnoidal haemorrhage, or intracerebral haemorrhage which are reported in 39\%, $34 \%$ and $20 \%$ of cases, respectively. ${ }^{116}$ In PRES, brain MRI may show vasogenic oedema in the parieto-occipital region (70\%), often with a symmetrical bihemispheric distribution which is contrasting with PML (figure 4, table 1). ${ }^{117}$ RCVS and PRES show very similar findings on cerebral angiography: segmental narrowing and dilatation, often bilateral, resembling a string of beads. As RCVS and PRES follow a very rapid course, screening via MRI is not an option. However, clinical awareness and early detection and recognition of these conditions by MRI is important as eliminating the triggering factor (DMT for MS in this case) might improve the outcome.

\section{Primary central nervous system lymphoma}

Primary central nervous system lymphoma (PCNSL) is a very rare non-Hodgkin's lymphoma, with an estimated incidence of 1.6 per 1000000 per year. ${ }^{118}$ Although the initial response to chemotherapy and radiation therapy is generally good, long-term

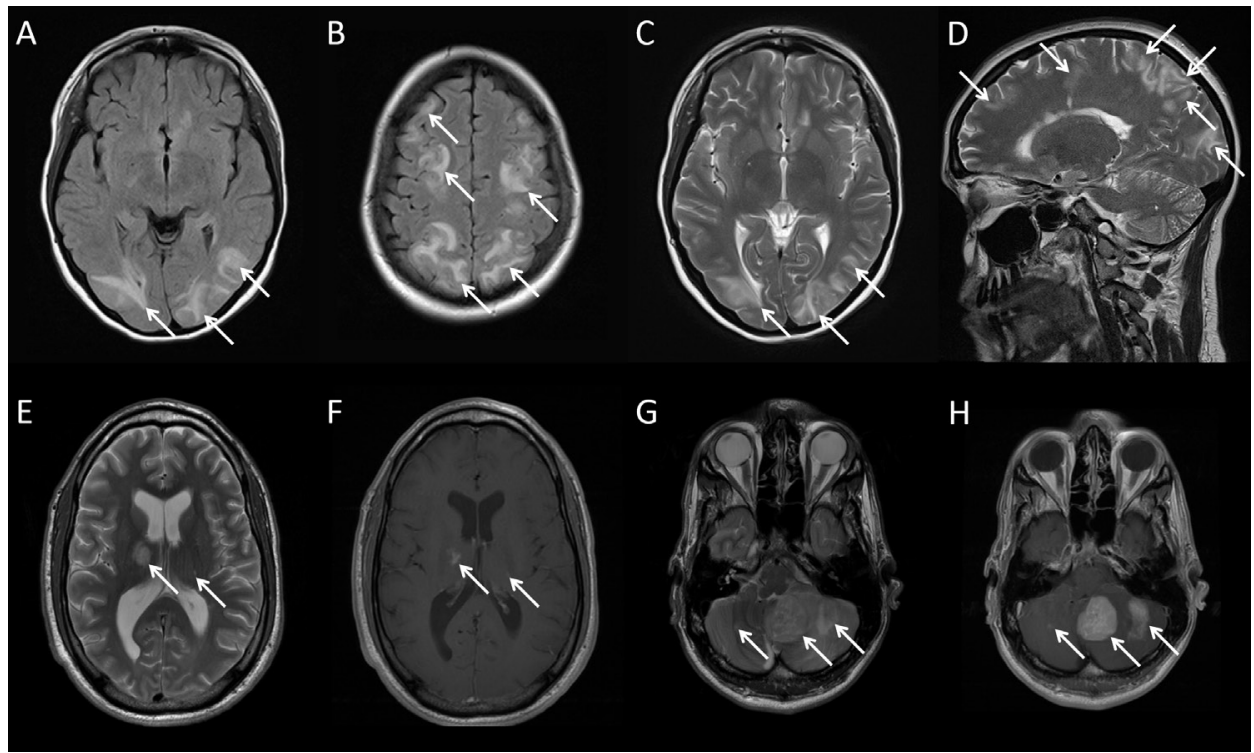

Figure $4 \quad \mathrm{MRI}$ of a patient with posterior reversible encephalopathy syndrome as a consequence of glomerulonephritis secondary to treatment with alemtuzumab $(A-D)$ and an MRI of a patient with primary central nervous system lymphoma during treatment with fingolimod $(E-H)$. Axial fluid attenuation inversion recovery (FLAIR) (A, B) and T2 (C), and sagittal T2 images (D). The image shows bilateral, subcortical and more or less symmetrical, FLAIR and T2 hyperintense lesions characteristic of vasogenic oedema in the occipital, parietal and frontal lobes. Axial T2 ( $E, G)$ and contrast enhanced T1 images (,$H$, . Multifocal and bilateral T2 hyperintense lesions in the cerebellum, thalamus and nucleus caudatus, showing homogeneous contrast enhancement. The left cerebellar lesion shows significant mass effect. 


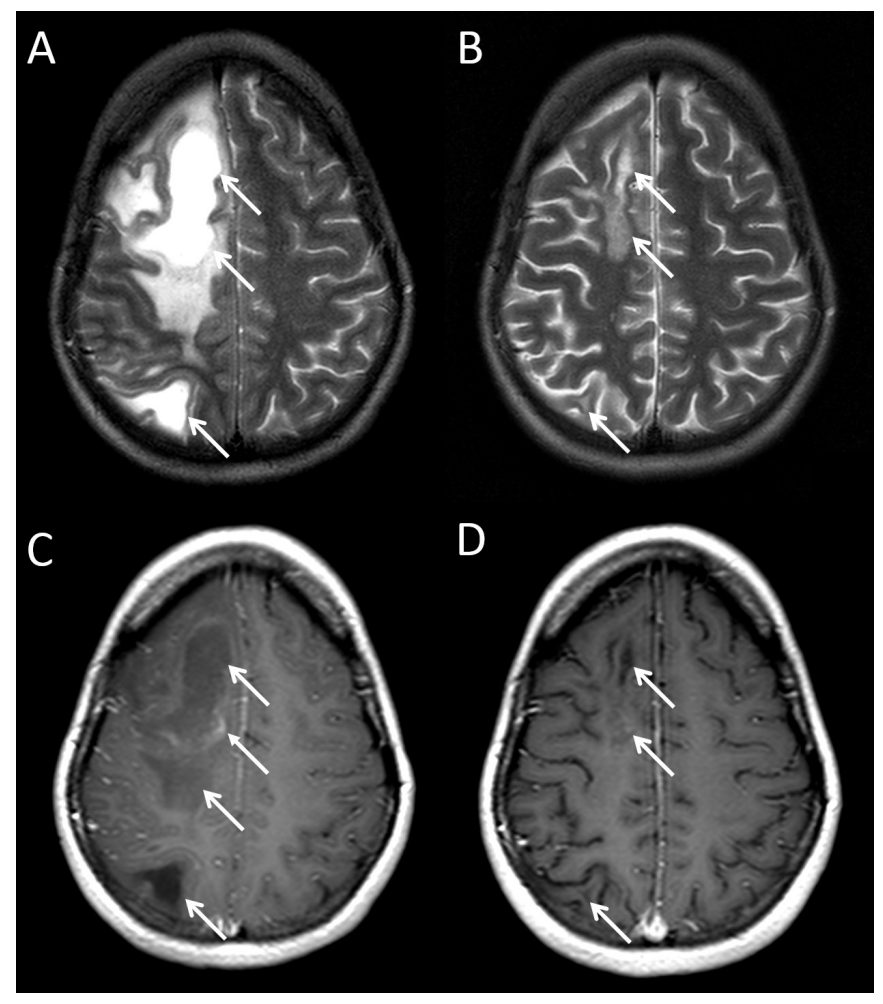

Figure $5 \mathrm{MRI}$ of a patient with tumefactive demyelinating lesions during treatment with fingolimod. Axial T2 (A, B) and contrast enhanced T1 images (C, D). A large demyelinating T2 hyperintense lesion in the right frontal, parietal and occipital lobes with significant mass effect and surrounding oedema is visible. The lesion shows a hypointense signal on T1 with contrast enhancement in the border of the lesion (A, C). Two months later the lesion has significantly deceased and no longer shows mass effect or contrast enhancement $(B, D)$.

prognosis is relatively poor. PCNSL has been reported with a higher incidence in immunocompromised patients, such as HIV/ AIDS and immunosuppressive treatments, and in senescence.

\section{PCNSL in MS therapies}

Since the first report by Schweikert et al in 2009, accumulating case reports and case series suggest that PCNSL is a rare complication of natalizumab treatment. ${ }^{119}{ }^{120}$ Remarkably, PCNSL has been reported in EBV positive and negative natalizumab-treated patients (at least three out of eight in the current case series were EBV negative), and following a relatively short treatment duration ( $\leq 7$ doses in all but one case). ${ }^{119}$ The mechanism by which immunosuppression may induce PCNSL in EBV negative patients remains to be elucidated. Diminished immunological surveillance by T-lymphocytes induced by natalizumab treatment may be involved. More recently, a case of T-cell PCNSL has also been described during treatment with fingolimod. ${ }^{121}$

\section{MRI pharmacovigilance}

In general, PCNSL is characterised by single lesions (63\% of cases), predominantly located in the periventricular areas or deep grey matter, with homogenous contrast enhancement and mild oedema (figure 4, table 1). ${ }^{122}$ In immunocompromised patients, however, PCNSL more often presents with a multifocal pattern with central necrosis and ring enhancement. ${ }^{123}$ Screening for PCNSL by frequent MRI studies will not be effective given the low incidence and rapid evolution of PCNSL. Recognition of PCNSL on MRI, and discriminating PCNSL from tumefactive demyelinating lesions (TDL), is essential in view of the conflicting treatment options.

\section{Neuroinflammation}

(Re)activation of neuroinflammation in MS therapies

Following both the initiation and cessation of fingolimod, severe clinical deterioration accompanied by TDL has been reported. ${ }^{124-129}$ In addition, natalizumab treatment has been associated with TDL. ${ }^{130-133}$ Induced lymphocyte subset shift or rapid lymphocyte influx into the CNS and natalizumab neutralising antibodies have been suggested to play a role in TDL development with fingolimod and natalizumab, respectively. ${ }^{132} 134$ Furthermore, over a dozen cases have been reported showing a severe clinical and radiological MS disease activity 6 months following a first alemtuzumab cycle, ${ }^{135} 136$ which is likely preceded by an abnormal B-cell reconstitution and responds strongly to B-cell/humoral focused therapy (eg, plasmapheresis and rituximab). ${ }^{136}$ Interestingly, a case of autoimmune encephalitis 8 months following a second alemtuzumab cycle was reported more recently, again responding well to B-cell depleting therapy. ${ }^{137} 138$

\section{MRI pharmacovigilance}

TDL presents as a large, tumor-like, demyelinating brain lesion showing open-ring enhancement, in contrast to most malignant tumours and abscesses which often show closed-ring enhancement (figure 5 , table 1 ). In addition, TDL often shows oedema and mass effect, which contrasts with PML. ${ }^{134}$ Given the rapid lesion evolution leading to symptoms, MRI screening specifically for TDL will not be useful. Early recognition of the typical MRI characteristics of TDL during DMT is essential, as cessation of therapy may be the best option.

Drug reaction with eosinophilia and systemic symptoms Drug reaction with eosinophilia and systemic symptoms (DRESS) is a severe drug-induced reaction, manifesting with eosinophilia, fever, lymphadenopathy and multiorgan involvement, sometimes including CNS vasculitis, encephalitis and intracranial haemorrhage, usually after 2-12 weeks of drug exposure. ${ }^{139} 140$ In March 2018, the Pharmacovigilance Risk Assessment Committee of the EMA noted that at least 12 patients experienced autoimmune encephalitis (later attributed to DRESS) during treatment with daclizumab, a humanised monoclonal antibody binding to $\mathrm{CD} 25$, which led to the withdrawal of daclizumab from the market by its manufacturer. ${ }^{141}$ MRI in these patients generally showed contrast enhancing lesions with a remarkable amount of vasogenic oedema. ${ }^{142} 143$ So far, no cases of DRESS syndrome have been reported in patients treated with other DMTs.

\section{Cerebrovascular events with alemtuzumab treatment}

Recently, the FDA released a safety communication on the occurrence of ischaemic or haemorrhagic stroke and cervical artery dissection in 13 patients treated with alemtuzumab. ${ }^{144}$ A recent study presented five of these cases, all showing intracranial haemorrhage on imaging very similar to haemorrhages with a hypertensive aetiology. ${ }^{145}$ The authors point out that alterations in hemodynamics are likely related in these patients as they are frequently observed during alemtuzumab treatment. The use of alemtuzumab has been restricted by the EMA pending a review of the drug. 
Table 2 Estimated risk of different disease-modifying treatments (DMTs) for infectious and non-infectious central nervous system adverse events in patients with multiple sclerosis

\begin{tabular}{|c|c|c|c|c|c|c|c|c|c|}
\hline & Alemtuzumab & Cladribine & Dimethylfumarate & Fingolimod & $\begin{array}{l}\text { Glatiramere } \\
\text { acetate }\end{array}$ & $\begin{array}{l}\text { Interferon } \\
\text { beta }\end{array}$ & Natalizumab & Ocrelizumab & Teriflunomide \\
\hline $\begin{array}{l}\text { JCV-associated } \\
\text { diseases }\end{array}$ & + & - & ++ & +++ & - & \pm & ++++ & + & - \\
\hline Herpesviruses & $+^{*}$ & $-^{*}$ & + & $++^{*}$ & - & - & +++ & + & - \\
\hline Cryptococcus & - & - & + & ++ & - & - & + & - & - \\
\hline Listeriosis & $++^{*}$ & - & + & + & - & - & - & - & - \\
\hline Nocardiosis & + & - & - & - & - & - & - & - & - \\
\hline RCVS & - & - & - & + & - & + & - & - & - \\
\hline PRES & - & - & - & ++ & - & - & + & - & - \\
\hline PCNSL & - & - & - & + & - & - & ++ & - & - \\
\hline $\begin{array}{l}\text { Cerebrovascular } \\
\text { eventst }\end{array}$ & ++ & - & - & - & - & - & - & - & - \\
\hline TDL & - & - & - & ++ & - & - & ++ & - & - \\
\hline
\end{tabular}

- no reported association; \pm cases reported but link obscured because of comedication or comorbidity (eg, with carry-over progressive multifocal leukoencephalopathy); + only few case reports

( $\leq 3$ cases reported in literature); ++ several case reports or case series ( $>3$ but $<20$ reported cases); +++ established but rare risk $(\geq 20$ but $<50$ reported cases); ++++ ignificant risk $(\geq 50$ reported cases).,

Limitation: the DMTs listed substantially differ in overall exposure, as such long-term safety aspects may change over time in particular for newer DMTs such as cladribine with limited postmarketing experience.

${ }^{*}$ Risk may be minimised by institution of prophylactic therapy or vaccination,

tCerebrovascular events include both ischaemic and haemorrhagic stroke, and cervical artery dissection.

JCV, JC virus; PCNSL, primary central nervous system lymphoma; PRES, posterior reversible encephalopathy syndrome; RCVS, reversible cerebral vasoconstriction syndrome; TDL, tumefactive demyelinating lesion.

\section{DISCUSSION}

With the introduction of effective immunosuppressive treatment options for MS, serious side effects of DMTs affecting the CNS have emerged. These include reactivation of primary infection with common pathogens such as JCV, HSV, VZV and Cryptococcus; de novo infections with VZV, Listeria and Nocardia, and non-infectious complications including PRES, RCVS, PCNSL, neuroinflammation, cerebrovascular events and DRESS (table 2). Although the potential benefits of DMTs are generally considered to outweigh the risks for these adverse events on a population level, these complications can be severely debilitating and life threatening for the individual. Early detection and diagnosis are essential, as this allows for timely therapeutic interventions, which almost always will include cessation of the DMT. In addition, specific and early initiation of antibiotics, antiviral medication, antifungal treatment, immune suppression or antitumor treatment regimens may improve the outcome, thereby diminishing the risk of irreversible neurological sequelae and death.

In addition to a detailed patient history and physical examination, suspicion of a CNS complication warrants brain MRI. Recognition of the specific MRI patterns of CNS complications is essential for a timely diagnosis and commencement of proper treatment. Moreover, different adverse events sometimes warrant contrasting therapeutic interventions which may even be detrimental when applied for a misdiagnosis (eg, corticosteroids in a patient with CNS infection when TDL is wrongfully suspected).

Regular brain MRIs as part of pharmacovigilance have been introduced for the follow-up of natalizumab-treated patients at high risk for developing PML, although the cost-benefit ratio is still a matter of debate. ${ }^{34344647}$ For example, the most recent risk stratification estimates that for patients who are anti-JCV antibody positive with an antibody index level of $>1.5$ and without prior immunosuppressive treatment, 2.6 and 10 per 1000 patients will develop PML in the third and sixth year of treatment, respectively. ${ }^{27}$ In other words, 385 or 100 patients need to be monitored before one case of PML develops in the third or sixth year of treatment. When performing a pharmacovigilance
MRI four times a year, this would result in 1540 or 400 MRIs, respectively, and, in the Netherlands, €408 100, or €106 000, per patient with new natalizumab-associated PML (average cost of a brain MRI: $€ 265$ ). On the other hand, a recent study quantified the positive impact on clinical outcome of frequent MRI screening. ${ }^{43}$ The authors showed that MRI surveillance every 3 to 4 months led to a significantly lower increase in disability due to PML than those with MRI assessment every 6-12 months (median expanded disability status scale increase of 0.5 vs 2.25). Further studies into the cost effectiveness of MRI screening should further include prizing of reduction of disability and mortality as well as costs of medication. Regular brain MRI for pharmacovigilance of all other DMT related, non-JCV associated, adverse events affecting the CNS does not seem to be justifiable as these are rare and carry a low cost-benefit ratio. Clinical vigilance therefore remains paramount.

\section{Author affiliations}

'Department of Neurology, MS Center Amsterdam, Neuroscience Amsterdam, Amsterdam UMC, Vrije Universiteit, Amsterdam, The Netherlands

${ }^{2}$ Department of Radiology \& Nuclear Medicine, MS Center Amsterdam,

Neuroscience Amsterdam, Amsterdam UMC, Vrije Universiteit, Amsterdam, The Netherlands

${ }^{3}$ Department of Neurology, University Hospital Köln, University of Cologne, Köln, Germany

${ }^{4}$ Department of Neurology, Medical Faculty, Heinrich Heine University, Dusseldorf, Germany

${ }^{5}$ Department of Neurology, St Vincent's University Hospital \& University College Dublin, Dublin, Ireland

${ }^{6}$ Department of Neurological Sciences, Division of Neuroinfectious Diseases, Rush University Medical Center, Chicago, Illinois, USA

${ }^{7}$ Institutes of Neurology and Healthcare Engineering, UCL, London, UK

${ }^{8}$ Department of Diagnostic and Interventional Neuroradiology, Hannover Medical School, Hannover, Germany

Correction notice This article has been corrected since it appeared Online First. Figure 4 has been corrected.

Acknowledgements The authors wish to thank Luca Prosperini, Patricia Mulero, Alex Rovira, Lutz Achtnichts, Krassen Nedeltchev, Horst Penkert, Thomas Korn, and their patients for the imaging data of cases presented in this review.

Contributors MTW and MPW provided the initial idea and outline of content for the manuscript. All authors contributed content and critically reviewed and edited 
the manuscript. MTW submitted the study and is responsible for the overall content as guarantor.

Funding The MS Centre Amsterdam is funded by a programme grant (14-358e) from the Stichting voor MS Research (Voorschoten, The Netherlands). CW received support from the Hertie foundation (P1150063). This work was supported in part by NIH grants R01 NS 047029 and NS 074995 to IJK.

Competing interests CW has received institutional fees for consultancy, speaking, or research from Novartis, Biogen, Sanofi-Genzyme and Roche; no personal fees within the last three years. CM has received consultancy or speaking fees from Actelion, Biogen, Merck, Novartis, Roche, Sandoz, Sanofi-Genzyme, Teva. IJK has received consultancy fees from Biogen, Regeneron and Agios Pharmaceuticals. JK has received consultancy fees from Merck-Serono, Teva, Biogen, Genzyme and Novartis. MPW has received consultancy fees from Biogen and Roche.

Patient consent for publication Not required.

Provenance and peer review Not commissioned; externally peer reviewed.

Supplemental material This content has been supplied by the author(s). It has not been vetted by BMJ Publishing Group Limited (BMJ) and may not have been peer-reviewed. Any opinions or recommendations discussed are solely those of the author(s) and are not endorsed by BMJ. BMJ disclaims all liability and responsibility arising from any reliance placed on the content. Where the content includes any translated material, BMJ does not warrant the accuracy and reliability of the translations (including but not limited to local regulations, clinical guidelines, terminology, drug names and drug dosages), and is not responsible for any error and/or omissions arising from translation and adaptation or otherwise.

\section{ORCID iDs}

Martijn T Wijburg http://orcid.org/0000-0002-0490-5638

Clemens Warnke http://orcid.org/0000-0002-3510-9255

\section{REFERENCES}

1 Warnke C, Olsson T, Hartung H-P. PML: the dark side of immunotherapy in multiple sclerosis. Trends Pharmacol Sci 2015;36:799-801.

2 Winkelmann A, Loebermann M, Reisinger EC, et al. Disease-modifying therapies and infectious risks in multiple sclerosis. Nat Rev Neurol 2016;12:217-33.

3 Wattjes MP, Rovira À, Miller D, et al. Evidence-based guidelines: MAGNIMS consensus guidelines on the use of MRI in multiple sclerosis--establishing disease prognosis and monitoring patients. Nat Rev Neurol 2015;11:597-606.

4 Rovira À, Wattjes MP, Tintoré M, et al. Evidence-based guidelines: MAGNIMS consensus guidelines on the use of MRI in multiple sclerosis-clinical implementation in the diagnostic process. Nat Rev Neurol 2015;11:471-82.

5 Tan CS, Koralnik IJ. Progressive multifocal leukoencephalopathy and other disorders caused by JC virus: clinical features and pathogenesis. Lancet Neurol 2010:9:425-37.

6 Chapagain ML, Nerurkar VR. Human polyomavirus JC (JCV) infection of human B lymphocytes: a possible mechanism for JCV transmigration across the blood-brain barrier. J Infect Dis 2010;202:184-91.

7 Gheuens S, Wüthrich C, Koralnik IJ. Progressive multifocal leukoencephalopathy: why gray and white matter. Annu Rev Pathol 2013;8:189-215.

8 Wijburg MT, van Oosten BW, Murk J-L, et al. Heterogeneous imaging characteristics of JC virus granule cell neuronopathy (Gcn): a case series and review of the literature. J Neurol 2015:262:65-73.

9 Du Pasquier RA, Corey S, Margolin DH, et al. Productive infection of cerebellar granule cell neurons by JC virus in an HIV + individual. Neurology 2003;61:775-82.

10 Wüthrich C, Dang X, Westmoreland S, et al. Fulminant JC virus encephalopathy with productive infection of cortical pyramidal neurons. Ann Neurol 2009;65:742-8.

11 Agnihotri SP, Wuthrich C, Dang X, et al. A fatal case of JC virus meningitis presenting with hydrocephalus in a human immunodeficiency virus-seronegative patient. Ann Neurol 2014;76:140-7.

12 Jelcic I, Jelcic I, Faigle W, et al. Immunology of progressive multifocal leukoencephalopathy. J Neurovirol 2015;21:614-22.

13 Brew BJ, Davies NWS, Cinque P, et al. Progressive multifocal leukoencephalopathy and other forms of JC virus disease. Nat Rev Neurol 2010:6:667-79.

14 Maas RPPWM, Muller-Hansma AHG, Esselink RAJ, et al. Drug-associated progressive multifocal leukoencephalopathy: a clinical, radiological, and cerebrospinal fluid analysis of 326 cases. I Neurol 2016;263:2004-21.

15 Miskin DP, Ngo LH, Koralnik IJ. Diagnostic delay in progressive multifocal leukoencephalopathy. Ann Clin Transl Neurol 2016;3:386-91.

16 Polman $\mathrm{CH}, \mathrm{O}^{\prime} \mathrm{Connor} \mathrm{PW}$, Havrdova E, et al. A randomized, placebo-controlled trial of natalizumab for relapsing multiple sclerosis. N Engl J Med 2006;354:899-910.

17 Biogen. Tysabri update / physician information. Available: http://medinfo.biogen.com [Accessed 23 Jun 2020].

18 Personal communication with Biogen 2020.

19 Personal communication with Novartis 2020

20 Berger JR, Cree BA, Greenberg B, et al. Progressive multifocal leukoencephalopathy after fingolimod treatment. Neurology 2018;90:e1815-21.
21 Gieselbach R-J, Muller-Hansma AH, Wijburg MT, et al. Progressive multifocal leukoencephalopathy in patients treated with fumaric acid esters: a review of 19 cases. J Neurol 2017;264:1155-64.

22 Gerevini S, Capra R, Bertoli D, et al. Immune profiling of a patient with alemtuzumab-associated progressive multifocal leukoencephalopathy. Mult Scler 2019:25:1196-201.

23 Personal communication with Roche 2020.

24 Fine AJ, Sorbello A, Kortepeter C, et al. Progressive multifocal leukoencephalopathy after natalizumab discontinuation. Ann Neurol 2014;75:108-15.

25 Blankenbach K, Schwab N, Hofner B, et al. Natalizumab-associated progressive multifocal leukoencephalopathy in Germany. Neurology 2019;92:e2232-9.

26 Giovannoni G, Marta M, Davis A, et al. Switching patients at high risk of PML from natalizumab to another disease-modifying therapy. Pract Neurol 2016;16:389-93.

27 Ho P-R, Koendgen H, Campbell N, et al. Risk of natalizumab-associated progressive multifocal leukoencephalopathy in patients with multiple sclerosis: a retrospective analysis of data from four clinical studies. Lancet Neurol 2017; 16:925-33.

28 Ryerson LZ, Foley J, Chang I, et al. Risk of natalizumab-associated PML in patients with MS is reduced with extended interval dosing. Neurology 2019;93:e145 2-e1462.

29 Scarpazza C, De Rossi N, Tabiadon G, et al. Four cases of natalizumab-related PML: a less severe course in extended interval dosing? Neurol Sci 2019;40:2119-24.

30 Balak DMW, Hajdarbegovic E, Bramer WM, et al. Progressive multifocal leukoencephalopathy associated with fumaric acid esters treatment in psoriasis patients. J Eur Acad Dermatol Venereol 2017;31:1475-82.

31 Nieuwkamp DJ, Murk J-L, van Oosten BW, Cremers CHP, et al. PML in a patient without severe lymphocytopenia receiving dimethyl fumarate. $N$ Engl I Med 2015:372:1474-6.

32 Schweitzer F, Laurent S, Fink GR, et al. Age and the risks of high-efficacy disease modifying drugs in multiple sclerosis. Curr Opin Neurol 2019;32:305-12.

33 Prosperini L, Scarpazza C, Imberti L, et al. Age as a risk factor for early onset of natalizumab-related progressive multifocal leukoencephalopathy. J Neurovirol 2017:23:742-9

34 Yousry TA, Pelletier D, Cadavid D, et al. Magnetic resonance imaging pattern in natalizumab-associated progressive multifocal leukoencephalopathy. Ann Neurol 2012;72:779-87.

35 Wattjes MP, Vennegoor A, Steenwijk MD, et al. MRI pattern in asymptomatic natalizumab-associated PML. J Neurol Neurosurg Psychiatry 2015;86:793-8.

36 Wijburg MT, Witte BI, Vennegoor A, et al. Mri criteria differentiating asymptomatic PML from new MS lesions during natalizumab pharmacovigilance. J Neurol Neurosurg Psychiatry 2016;87:1138-45.

37 Hodel J, Outteryck O, Dubron C, et al. Asymptomatic progressive multifocal leukoencephalopathy associated with natalizumab: diagnostic precision with MR imaging. Radiology 2016;278:863-72.

38 Hodel J, Darchis C, Outteryck O, et al. Punctate pattern: a promising imaging marker for the diagnosis of natalizumab-associated PML. Neurology 2016;86:1516-23.

39 Wattjes MP, Wijburg MT, van Eijk J, et al. Inflammatory natalizumab-associated PML: baseline characteristics, lesion evolution and relation with PML-IRIS. J Neurol Neurosurg Psychiatry 2018;89:535-41

40 Richert N, Bloomgren G, Cadavid D, et al. Imaging findings for PML in natalizumabtreated MS patients. Mult Scler 2012;18:27-8.

41 Wijburg MT, Siepman D, van Eijk JJJ, et al. Concomitant granule cell neuronopathy in patients with natalizumab-associated PML. J Neurol 2016;263:649-56.

42 Sorensen PS, Koch-Henriksen N, Petersen T, et al. Recurrence or rebound of clinical relapses after discontinuation of natalizumab therapy in highly active MS patients. J Neurol 2014;261:1170-7.

43 Scarpazza C, Signori A, Cosottini M, et al. Should frequent MRI monitoring be performed in natalizumab-treated MS patients? A contribution to a recent debate. Mult Scler 2020:26:1227-36.

44 Scarpazza C, Signori A, Prosperini L, et al. Early diagnosis of progressive multifocal leucoencephalopathy: Iongitudinal lesion evolution. I Neurol Neurosurg Psychiatry 2019;90:261-7.

45 Dong-Si T, Richman S, Wattjes MP, et al. Outcome and survival of asymptomatic PML in natalizumab-treated MS patients. Ann Clin Trans/ Neurol 2014;1:755-64.

46 McGuigan C, Craner M, Guadagno J, et al. Stratification and monitoring of natalizumab-associated progressive multifocal leukoencephalopathy risk: recommendations from an expert group. I Neurol Neurosurg Psychiatry 2016;87:117-25

47 Enzinger C. High-frequency MRI monitoring should be performed in natalizumabtreated MS patients with higher risk of PML - NO. Mult Scler 2017;23:767-70.

48 Wattjes MP, Wijburg MT, Vennegoor A, et al. Diagnostic performance of brain MRI in pharmacovigilance of natalizumab-treated MS patients. Mult Scler 2016;22:1174-83.

49 Berger JR, Aksamit AJ, Clifford DB, et al. Pml diagnostic criteria: consensus statement from the AAN Neuroinfectious disease section. Neurology 2013;80:1430-8.

50 Kuhle J, Gosert R, Bühler R, et al. Management and outcome of CSF-JC virus PCR-negative PML in a natalizumab-treated patient with MS. Neurology 2011;77:2010-6. 
51 Wijburg MT, Warnke C, Barkhof F, et al. Performance of PML diagnostic criteria in natalizumab-associated PML: data from the Dutch-Belgian cohort. J Neurol Neurosurg Psychiatry 2019;90:44-6.

52 Wijburg MT, Kleerekooper I, Lissenberg-Witte BI, et al. Association of progressive multifocal leukoencephalopathy lesion volume with JC virus polymerase chain reaction results in cerebrospinal fluid of natalizumab-treated patients with multiple sclerosis. JAMA Neurol 2018;75:827.

53 Warnke C, von Geldern G, Markwerth P, et al. Cerebrospinal fluid JC virus antibody index for diagnosis of natalizumab-associated progressive multifocal leukoencephalopathy. Ann Neurol 2014;76:792-801.

54 Warnke C, Wijburg MT, Hartung H-P, et al. Application of the CSF JCV antibody index to early natalizumab-associated progressive multifocal leukoencephalopathy. $J$ Neurol Neurosurg Psychiatry 2017;88:1092-4.

55 Wijburg MT, Warnke C, Killestein J, et al. Application of "Mentzer's PML case definition" to natalizumab-treated patients in the setting of strict MRI-based pharmacovigilance. J Neurol 2020;267:2599-602.

56 World Health Organisation. Herpes simplex virus. Available: http://www.who.int/ mediacentre/factsheets/fs400/en/ [Accessed 10 Oct 2017].

57 Whitley RJ. Herpes simplex encephalitis: adolescents and adults. Antiviral Res 2006;71:141-8.

58 Solomon T, Michael BD, Smith PE, et al. Management of suspected viral encephalitis in adults - association of British neurologists and British Infection Association national guidelines. J Infect 2012;64:347-73.

59 Fine AJ, Sorbello A, Kortepeter C, et al. Central nervous system herpes simplex and varicella zoster virus infections in natalizumab-treated patients. Clin Infect Dis 2013;57:849-52.

60 Yeung J, Cauquil C, Saliou G, et al. Varicella-zoster virus acute myelitis in a patient with MS treated with natalizumab. Neurology 2013;80:1812-3.

61 Kobeleva X, Wegner F, Brunotte I, et al. Varicella zoster-associated retinal and central nervous system vasculitis in a patient with multiple sclerosis treated with natalizumab. J Neuroinflammation 2014;11:19.

62 Mulero P, Auger C, Parolin L, et al. Varicella-zoster meningovasculitis in a multiple sclerosis patient treated with natalizumab. Mult Scler 2018;24:358-60.

63 Ratchford JN, Costello K, Reich DS, et al. Varicella-zoster virus encephalitis and vasculopathy in a patient treated with fingolimod. Neurology 2012;79:2002-4

64 Issa NP, Hentati A. Vzv encephalitis that developed in an immunized patient during fingolimod therapy. Neurology 2015;84:99-100.

65 Harrer A, Wipfler P, Pilz G, et al. Adaptive immune responses in a multiple sclerosis patient with acute varicella-zoster virus reactivation during treatment with fingolimod. Int J Mol Sci 2015;16:21832-45.

66 Cohen JA, Barkhof F, Comi G, et al. Oral fingolimod or intramuscular interferon for relapsing multiple sclerosis. N Engl J Med 2010;362:402-15.

67 Arvin AM, Wolinsky JS, Kappos L, et al. Varicella-zoster virus infections in patients treated with fingolimod: risk assessment and consensus recommendations for management. JAMA Neurol 2015;72:31-9.

68 Pfender N, Jelcic I, Linnebank M, et al. Reactivation of herpesvirus under fingolimod: a case of severe herpes simplex encephalitis. Neurology 2015;84:2377-8.

69 Perini P, Rinaldi F, Puthenparampil M, et al. Herpes simplex virus encephalitis temporally associated with dimethyl fumarate-induced lymphopenia in a multiple sclerosis patient. Mult Scler Relat Disord 2018;26:68-70.

70 Cook S, Vermersch P, Comi G, et al. Safety and tolerability of cladribine tablets in multiple sclerosis: the clarity (cladribine tablets treating multiple sclerosis orallY) study. Mult Scler 2011;17:578-93.

71 Hauser SL, Bar-Or A, Comi G, et al. Ocrelizumab versus interferon beta-1a in relapsing multiple sclerosis. N Eng/ J Med 2017;376:221-34.

72 Havrdova E, Arnold DL, Cohen JA, et al. Alemtuzumab CARE-MS I 5-year follow-up: durable efficacy in the absence of continuous MS therapy. Neurology 2017;89:1107-16.

73 Dudek MIR, Thies K, Kammenhuber S, et al. HSV-2-encephalitis in a patient with multiple sclerosis treated with ocrelizumab. J Neurol 2019;266:2322-3.

74 Wasay M, Mekan SF, Khelaeni B, et al. Extra temporal involvement in herpes simplex encephalitis. Eur J Neurol 2005;12:475-9.

75 Tan IL, McArthur JC, Venkatesan A, et al. Atypical manifestations and poor outcome of herpes simplex encephalitis in the immunocompromised. Neurology 2012;79:2125-32.

76 De Broucker T, Mailles A, Chabrier S, et al. Acute varicella zoster encephalitis without evidence of primary vasculopathy in a case-series of 20 patients. Clin Microbiol Infect 2012;18:808-19.

77 Pyrgos V, Seitz AE, Steiner CA, et al. Epidemiology of cryptococcal meningitis in the US: 1997-2009. PLoS One 2013:8:e56269.

78 Alanio A, Vernel-Pauillac F, Sturny-Leclère A, et al. Cryptococcus neoformans host adaptation: toward biological evidence of dormancy. mBio 2015;6:e02580-14.

79 Park BJ, Wannemuehler KA, Marston BJ, et al. Estimation of the current global burden of cryptococcal meningitis among persons living with HIVIAIDS. AIDS 2009;23:525-30

80 Achtnichts L, Obreja O, Conen A, et al. Cryptococcal meningoencephalitis in a patient with multiple sclerosis treated with fingolimod. JAMA Neurol 2015;72:1203-5.
81 Ma SB, Griffin D, Boyd SC, et al. Cryptococcus neoformans var grubii meningoencephalitis in a patient on fingolimod for relapsing-remitting multiple sclerosis: case report and review of published cases. Mult Scler Relat Disord 2020;39:101923.

82 Wienemann T, Müller A-K, MacKenzie C, et al. Cryptococcal meningoencephalitis in an $\lg \mathrm{G}_{2}$-deficient patient with multiple sclerosis on fingolimod therapy for more than five years - case report. BMC Neurol 2020;20:158.

83 Grebenciucova E, Reder AT, Bernard JT. Immunologic mechanisms of fingolimod and the role of immunosenescence in the risk of cryptococcal infection: a case report and review of literature. Mult Scler Relat Disord 2016;9:158-62.

84 Valenzuela RM, Pula JH, Garwacki D, et al. Cryptococcal meningitis in a multiple sclerosis patient taking natalizumab. J Neuro/ Sci 2014;340:109-11.

85 Gundacker ND, Jordan SJ, Jones BA, et al. Acute cryptococcal immune reconstitution inflammatory syndrome in a patient on natalizumab. Open Forum Infect Dis 2016;3:ofw038.

86 Workel HH, Wolfhagen MJHM, Bouwhuis JW, et al. Cryptococcal meningitis in a patient with multiple sclerosis on dimethyl fumarate treatment: a case report. Mult Scler Relat Disord 2020;42:102137.

87 Wingfield T, Jani M, Krutikov M, et al. Cryptococcal meningitis in an HIVnegative patient with rheumatoid arthritis treated with rituximab. Rheumatology 2011;50:1725-7.

88 Dinçol G, Kahraman R. Cryptococcus neoformans meningitis in a patient with hairy cell leukemia. Am J Hematol 2006;81:387.

89 Ingram PR, Howman R, Leahy MF, et al. Cryptococcal immune reconstitution inflammatory syndrome following alemtuzumab therapy. Clin Infect Dis 2007;44:e115-7.

90 Zhong Y, Zhou Z, Fang X, et al. Magnetic resonance imaging study of cryptococcal neuroradiological lesions in HIV-negative cryptococcal meningitis. Eur J Clin Microbiol Infect Dis 2017;36:1367-72.

91 Swaminathan B, Gerner-Smidt P. The epidemiology of human listeriosis. Microbes Infect 2007;9:1236-43.

92 Holmøy T, von der Lippe H, Leegaard TM. Listeria monocytogenes infection associated with alemtuzumab - - a case for better preventive strategies. BMC Neurol 2017;17:65.

93 Calame DG, Mueller-Ortiz SL, Wetsel RA. Innate and adaptive immunologic functions of complement in the host response to Listeria monocytogenes infection. Immunobiology 2016;221:1407-17.

94 Thomas K, Eisele J, Rodriguez-Leal FA, et al. Acute effects of alemtuzumab infusion in patients with active relapsing-remitting MS. Neurol Neuroimmunol Neuroinflamm 2016;3:e228.

95 Ruggieri S, Logoteta A, Martini G, et al. Listeria monocytogenes-Induced rhombencephalitis in a patient with multiple sclerosis treated with dimethyl fumarate. JAMA Neurol 2018;75:762-3.

96 Tecellioglu M, Kamisli 0, Kamisli S, et al. Listeria monocytogenes rhombencephalitis in a patient with multiple sclerosis during fingolimod therapy. Mult Scler Relat Disord 2019;27:409-11.

97 Onder ME, Gun H, Kimyon G, et al. Brain abscesses due to Listeria monocytogenes after rituximab therapy. J Clin Rheumatol 2016;22:233-4.

98 Kayaaslan BU, Akinci E, Bilen S, et al. Listerial rhombencephalitis in an immunocompetent young adult. Int J Infect Dis 2009;13:e65-7.

99 Association of British Neurologists. Guidelines on the prevention of Listeria infection after alemtuzumab treatment from the association of British neurologists. Available: https://www.theabn.org/news/new-guidelines-on-the-prevention-of-listeriainfection.html [Accessed 28 Jul 2018].

100 Fatahi-Bafghi M. Nocardiosis from 1888 to 2017. Microb Pathog 2018;114:369-84.

101 Rafiei N, Peri AM, Righi E, et al. Central nervous system nocardiosis in Queensland: a report of 20 cases and review of the literature. Medicine 2016;95:e5255.

102 Penkert H, Delbridge C, Wantia N, et al. Fulminant central nervous system nocardiosis in a patient treated with alemtuzumab for relapsing-remitting multiple sclerosis. JAMA Neurol 2016;73:757-9.

103 Sheikh-Taha M, Corman LC. Pulmonary Nocardia beijingensis infection associated with the use of alemtuzumab in a patient with multiple sclerosis. Mult Scler 2017;23:872-4

104 Ngiu CS, Said MSM, Periyasamy P, et al. Nocardiosis in a patient with rheumatoid athritis treated with rituximab and a summary of reported cases. Case Rep Child Meml Hosp Chic 2010;2010:bcr1120092421.

105 Beaman BL, Beaman L. Nocardia species: host-parasite relationships. Clin Microbiol Rev 1994;7:213-64.

106 Ducros A. Reversible cerebral vasoconstriction syndrome. Lancet Neurol 2012;11:906-17.

107 Fugate JE, Rabinstein AA. Posterior reversible encephalopathy syndrome: clinical and radiological manifestations, pathophysiology, and outstanding questions. Lancet Neurol 2015;14:914-25.

108 Cappelen-Smith C, Calic Z, Cordato D. Reversible cerebral vasoconstriction syndrome: recognition and treatment. Curr Treat Options Neurol 2017;19:21.

109 Belliston S, Sundararajan J, Hammond N, et al. Reversible cerebral vasoconstriction syndrome in association with fingolimod use. Int J Neurosci 2017;127:1-4. 
110 Kraemer M, Weber R, Herold M, et al. Reversible cerebral vasoconstriction syndrome associated with fingolimod treatment in relapsing-remitting multiple sclerosis three months after childbirth. Mult Scler 2015;21:1473-5.

111 Strohm T, Chaudhry B, Willis MA, et al. Reversible cerebral vasoconstriction syndrome associated with interferon beta-1a use for multiple sclerosis. Mult Scler 2016;22:1626-8.

112 Lindå $H$, von Heijne A. A case of posterior reversible encephalopathy syndrome associated with gilenya $(\circledR)$ (fingolimod) treatment for multiple sclerosis. Front Neurol 2015;6:39.

113 Décard BF, Haghikia A, Tönnes C, et al. Natalizumab-associated reversible encephalopathy syndrome mimicking progressive multifocal leukoencephalopathy. Mult Scler 2013;19:249-51.

114 Morrow SA, Rana R, Lee D, et al. Posterior reversible encephalopathy syndrome due to high dose corticosteroids for an MS relapse. Case Rep Neurol Med 2015:2015:1-4.

115 World Health Organization. VigiAccess ${ }^{\mathrm{TM}}$. Available: http://www.vigiaccess.org/ [Accessed 6 Jul 2020].

116 Singhal AB, Hajj-Ali RA, Topcuoglu MA, et al. Reversible cerebral vasoconstriction syndromes: analysis of 139 cases. Arch Neurol 2011:68:1005-12.

117 Fischer M, Schmutzhard E. Posterior reversible encephalopathy syndrome. J Neurol 2017;264:1608-16.

118 Grommes C, DeAngelis LM. Primary CNS lymphoma. J Clin Oncol 2017;35:2410-8.

119 Nixon M, Menger RP, Kalakoti P, et al. Natalizumab-Associated primary central nervous system lymphoma. World Neurosurg 2018;109:152-9.

120 Schweikert $A$, Kremer $M$, Ringel $F$, et al. Primary central nervous system lymphoma in a patient treated with natalizumab. Ann Neurol 2009;66:403-6.

121 de Jong BA, van Kempen ZLE, Wattjes MP, et al. Intracerebral lymphoproliferative disorder in an MS patient treated with fingolimod. Neurol Neuroimmunol Neuroinflamm 2018;5:e483.

122 Bühring U, Herrlinger U, Krings T, et al. Mri features of primary central nervous system lymphomas at presentation. Neurology 2001;57:393-6.

123 Küker W, Nägele T, Korfel A, et al. Primary central nervous system lymphomas (PCNSL): MRI features at presentation in 100 patients. J Neurooncol 2005;72:169-77.

124 Lapucci C, Baroncini D, Cellerino M, et al. Different MRI patterns in MS worsening after stopping fingolimod. Neurol Neuroimmunol Neuroinflamm 2019;6:e566.

125 Visser F, Wattjes MP, Pouwels PJW, et al. Tumefactive multiple sclerosis lesions under fingolimod treatment. Neurology 2012;79:2000-3.

126 Pilz G, Harrer A, Wipfler P, et al. Tumefactive MS lesions under fingolimod: a case report and literature review. Neurology 2013;81:1654-8.

127 Jander S, Turowski B, Kieseier BC, et al. Emerging tumefactive multiple sclerosis after switching therapy from natalizumab to fingolimod. Mult Scler 2012;18:1650-2.

128 Faissner S, Hoepner R, Lukas C, et al. Tumefactive multiple sclerosis lesions in two patients after cessation of fingolimod treatment. Ther Adv Neurol Disord 2015;8:233-8.
129 Salam S, Mihalova T, Siripurapu R. Severe tumefactive rebound of multiple sclerosis following fingolimod cessation. BMJ Case Rep 2016;2016:bcr2016215596.

130 Twyman C, Berger JR. A giant MS plaque mimicking PML during natalizumab treatment. J Neurol Sci 2010;291:110-3.

131 Berger JR. Paradoxically aggressive multiple sclerosis in the face of natalizumab therapy. Mult Scler 2008;14:708-10.

132 Debs R, Maillart E, Fahed R, et al. Extensive brain demyelinating lesions under natalizumab: the role of anti-natalizumab antibodies. Neurology 2015:85:1630-2.

133 Svenningsson A, Dring AM, Fogdell-Hahn A, et al. Fatal neuroinflammation in a case of multiple sclerosis with anti-natalizumab antibodies. Neurology 2013;80:965-7.

134 Algahtani $H$, Shirah B, Alassiri A. Tumefactive demyelinating lesions: a comprehensive review. Mult Scler Relat Disord 2017;14:72-9.

135 Wehrum T, Beume L-A, Stich 0, et al. Activation of disease during therapy with alemtuzumab in 3 patients with multiple sclerosis. Neurology 2018;90:e601-5.

136 Haghikia A, Dendrou CA, Schneider R, et al. Severe B-cell-mediated CNS disease secondary to alemtuzumab therapy. Lancet Neurol 2017;16:104-6.

137 Giarola B, Massey J, Barnett Y, et al. Autoimmune encephalitis following alemtuzumab treatment of multiple sclerosis. Mult Scler Relat Disord 2019;28:31-3.

138 Massey J, Barnett Y, Curnow J, et al. B cell depletion therapy resulting in sustained remission of severe autoimmune complications following alemtuzumab treatment of multiple sclerosis. Mult Scler Relat Disord 2019;35:100-3.

139 Cacoub P, Musette P, Descamps V, et al. The dress syndrome: a literature review. Am J Med 2011;124:588-97.

140 Gaha M, Landry D, Bélair M, et al. Dress syndrome: cerebral vasculitic-like presentation. Neuroradiology 2015;57:1015-21.

141 European Medicines Agency. Multiple sclerosis medicine Zinbryta suspended in the EU. Available: ema.europa.eu/ema/index.jspcurl=pages/medicines/human/referrals/ Zinbryta/human_refer ral_prac_000074.jsp\&mid=WC0b01ac05805c516f [Accessed 7 Mar 2018]

142 Rauer S, Stork L, Urbach H, et al. Drug reaction with eosinophilia and systemic symptoms after daclizumab therapy. Neurology 2018;91:e359-63.

143 Scheibe F, Metz I, Radbruch H, et al. Drug reaction with eosinophilia and systemic symptoms after daclizumab therapy in MS. Neurol Neuroimmunol Neuroinflamm 2018;5:e479.

144 FDA. FDA warns about rare but serious risks of stroke and blood vessel wall tears with multiple sclerosis drug Lemtrada (alemtuzumab). Available: https://www. fda.gov/drugs/drug-safety-and-availability/fda-warns-about-rare-serious-risksstroke-and-blood-vessel-wall-tears-multiple-sclerosis-drug?utm_campaign=FDA\% 20MedWatch\%20-\%20Lemtrada\%20\%28alemtuzumab\%29\%3A\%20Drug\% 20Safety\%20Communication\&utm_m edium=email\&utm_source=Eloqua [Accessed $21 \mathrm{Jul} 2019$.

145 Azevedo CJ, Kutz C, Dix A, et al. Intracerebral haemorrhage during alemtuzumab administration. Lancet Neurol 2019;18:329-31. 